\title{
INTRODUCTION TO THE ARCHITECTURAL PROJECT LEARNING
}

\author{
M.I. Alba Dorado \\ University of Malaga (SPAIN)
}

\begin{abstract}
The beginning of learning the architectural project is possibly one of the most memorable beginnings that any architect can undertake in his training. It is the starting point of an activity that will accompany you throughout your career. A learning that, in these early years of waking up to architectural creation, becomes exciting and intense.

This communication intends to formulate a way of operating in the teaching of architecture that supports the students' initiation in their learning of the projection process. The initiatory nature of this learning in the first courses of the Architectural Projects course implies the student's first contact with knowledge and the creation of architecture. The need to create a habit and an attitude towards the architectural project becomes fundamental in this phase of initiation.

In this sense, the present communication aims to define a series of specific and effective approaches in the teaching of the architectural project that, centered on the recognition of the student in the initial stages of his training as an architect, allows us to establish a series of training strategies that offer a progress in the teaching of the architectural project.

To do this, it is based on a teaching model of the subject of Architectural Projects that is conceived in a different way from what is usual in many Architecture Schools and that lies in subjecting the student to an almost military training, consisting of Offering an academic training based on a simulation of professional activity with the objective of allowing it in the future to face situations already known from established means, even being aware that such simulation is false.
\end{abstract}

The teaching of the architecture project in the first years of training should move away from the transmission of a pre-established teaching or a closed and complete architectural culture, possessing a strict and infallible method, capable of depleting the pathways of knowledge, to move towards a Active and plural teaching, based on continuous research, participates in an open, flexible and dynamic disciplinary discourse.

In this sense, as a work methodology we propose to define a series of training strategies whose presence in the first courses of the career are considered important as support to the student in his training as a future architect from the identification of certain attitudes and dispositions that are indispensable that the student adopts towards his learning.

The result will be the definition of a series of training strategies that define a teaching of the architectural project that addresses not only what you want to teach, but also how you are going to teach in order to design a teaching model that goes beyond the model traditional transmission of knowledge from the teacher to the student and that demands the active participation of the latter in their own training through the creation of learning situations in which information training prevails, that encourages and stimulates autonomous learning, encouraging the student to be actively involved in his learning, encouraging him to learn to learn.

Keywords: Architectural Projects, Active Methodologies, Learning Self-Regulation Methodologies, Critical Discipline, Experimental Pedagogy. 